\title{
Research on Bamboo Forest Ecotourism Development in Xianning City Based on SWOT Analysis
}

\author{
Guo Lei \\ School of Economics and Management \\ Hubei University of Automotive Technology, \\ Shiyan, China
}

\author{
Fu Chengyu \\ School of Economics and Management \\ Hubei University of Automotive Technology, \\ Shiyan, China
}

\begin{abstract}
As a special tourism project, bamboo forest ecotourism has broad market prospects and a strong development momentum. Xianning is know as the famous "hometown of bamboo" and has innate conditions for carrying out bamboo forest ecotourism. This paper analyzes the current situation of bamboo forest ecotourism development in Xianning City, summarizes the advantages, disadvantages, opportunities and threats of local bamboo forest ecotourism development, and proposes the development strategy for Xianning bamboo forest ecotourism, so as to promote the sustainable development of Xianning bamboo forest economy and ecotourism.
\end{abstract}

Keywords-SWOT; bamboo forest resources; bamboo forest eco-tourism; xianning city

\section{INTRODUCTION}

Profe well-known tourism expert and travel consultant of the US Federal Government, pointed out: "Ecotourism, followed by cultural tourism, participatory tourism and health tourism. ranks first among the four new types of tourism activities that will be popularized around the world." China is one of the countries with the most abundant bamboo resources in the world. Since the 1990s, bamboo forest tourism with bamboo forest resources as a tourist attraction has developed rapidly in many cities in China. Bamboo forest eco-tourism is green, and has a rich cultural connotation, which is very attractive to people [1].

Xianning City has a long history of cultivation of bamboo, and is known as the "hometown of bamboo". The city's existing bamboo forest resources cover an area of 1.6 million mu, accounting for $80 \%$ of the total area of bamboo forests in Hubei Province, ranking seventh in the national commodity bamboo production area. The bamboo industry has become an important industry for the city's economic development, and its development momentum is strong. At the same time, Xianning City is rich in tourism resources, profound in history and culture, and has excellent transportation system. It has unique advantages and conditions for developing bamboo forest ecotourism.

\section{DEVELOPMENT STATUS OF BAMBOO FOREST ECO- TOURISM IN XIANNING CITY}

Xianning City is known as the "Hometown of Bamboo" in central China. In recent years, in order to promote the bamboo forest economy, the Xianning Municipal Party Committee and the Municipal Government have formulated the "Xianning
Bamboo Industry Development Plan (2013-2020)". It is planned to develop the bamboo forest base to 1.8 million mu by 2020 , and realize the total output value of the bamboo industry to be 10 billion yuan, making the bamboo industry a pillar industry. At the same time, with the great attention and support of the municipal party committee and the municipal government, the overall tourism spatial pattern of "one core, two wings, four poles and four belts" with the urban area as the leader has taken shape. Based on the "13th Five-Year Development Plan for Tourism in Xianning City", Xianning City is actively building "a first-class, internationally renowned eco-cultural tourism destination". Therefore, the organic combination of bamboo forest industry and eco-tourism conforms to the needs of regional development and is of great practical significance.

Relying on abundant bamboo resources, Xianning City has invested a lot of manpower, material resources and financial resources, and has developed them successively. Bamboo forest scenic spots and attractions such as the Xingxing bamboo zone, Suiyang bamboo zone, Hongxia bamboo zone, and Qianshan Forest Park. It's planned to establish China's first bamboothemed "Bamboo Cube" museum in Xianning Qianshan National Forest Park. On the basis of exploring bamboo resources, Xianning City has also continuously improved the construction of tourism supporting facilities. After the development of Xingxing bamboo zone and Suiyang bamboo zone, the expansion of highways such as Wen Sui tourism highway has been finished, making transportation more convenient. Tourist billboards and signs are improved, perfecting the travel identification system. With the development of bamboo forest eco-tourism, the popularity of bamboo forest tourism in Xianning City has been continuously improved. In May 2017, the famous director Zhang Yimou filmed a new film "Shadow", in which the three bamboo zones were used.

In the development process of bamboo forest eco-tourism, Xianning is premised on protecting the landscape pattern, diversified natural landscape and diverse local cultural landscapes. Under the condition of not destroying the ecotourism environment, it promotes bamboo forest eco-tourism and creates green Xianning, with obvious results. However, in terms of its rich bamboo resources, the development of Xianning bamboo forest eco-tourism is still in its infancy. 


\section{SWOT ANALYSIS OF BAMBOO FOREST ECO-TOURISM DEVELOPMENT IN XIANNING CITY}

\section{A. Advantage analysis}

\section{1) Excellent ecosystem}

Xianning is an ecological leisure tourism city with rich products and suitable for travel. It is honored as the hometown of sweet-scented osmanthus, bamboo, ricin, tea and hot springs. It enjoys a reputation as the typical representative of ecological balance of natural resources of subtropical forests in China and is given the "Human Habitat Environment Model Award". The climate there is mild, rainfall abundant, sunshine sufficient, and the four seasons are distinct. The city's forest coverage rate is $52.3 \%$.The all year round air index is excellent, and the green ecology has become synonymous with Xianning. furthermore, rich geothermal hot spring resources cover throughout the city's six counties.

\section{2) Rich bamboo resources}

By the end of 2017, there are more than 15 kinds of bamboos in the city, with more than 15 kinds of bamboos. The area of newly-built bamboo forests has exceeded 120,000 $\mathrm{mu}$, the area of bamboo forest bases and parks has exceeded 1.65 million mu, and the annual output value of bamboo forest tourism has exceeded 700 million yuan. The main bamboo resources are: Xianan E'an bamboo zone, Damu bamboo zone, Chibi Yangyang bamboo zone, Chongyang Hongxia bamboo zone, Guihua forest farm, Tongshan Jiugong Mountain bamboo zone, etc. The bamboo forest resources in the area have their own characteristics. For example, the Xian'an District is dominated by bamboo, the Chibi City is dominated by Neosinocalamus affinis, and the Chongyang County by Lei bamboo. Bamboo forests in various regions have formed their own characteristics according to local conditions, providing a good resource base for bamboo forest ecological tourism in Xianning City.

\section{3) Splendid history and culture}

As a famous historical and cultural city in China, Xianning City has a long history and splendid culture. As early as 5,000 years ago in the Neolithic period, there were human beings living here, creating a splendid ancient civilization. Cultural resources include Jiugongshan Taoist culture, Jingchu opera culture, Yaogushan Yao ethnic culture, Zhoushang bronze culture, and Tingsiqiao revolutionary culture. The diverse culture provides rich cultural connotation for the development of Xianning eco-tourism. Xianning has a long history of bamboo cultivation. The mountains and rivers of Xianning have left countless poems. These cultural heritages are evidence of the profound bamboo culture of Xianning.

\section{4) Superior traffic location}

Xianning City is located in the southeastern part of Hubei Province, known as the "South Gate of Hubei". It is very close to Wuhan - the provincial capital-in the east. The transportation system is well developed, many highways, highspeed railways running through Xianning, which constitutes a fast and convenient tourist transportation network in Xianning.

\section{B. Disadvantage analysis}

\section{1) Lack of in-depth tourism development}

Although there are abundant bamboo forest resources in Xianning City, the overall development of bamboo forest ecotourism is relatively too extensive and the characteristics are not obvious. In the development of tourism, the traditional model of mass tourism persists. Many tourist attractions have completely equated bamboo forest tourism to eco-tourism. At the same time, the essence of bamboo culture is yet to be tapped into, and the perfect connection between eco-tourism and bamboo culture is yet to be established. Consequently, it has led to the monotony of tourism products in the scenic spots, without manifestation of bamboo culture. For example, Chongyang Hongxia Bamboo Forest Scenic Area and Tongshan Bamboo Forest Scenic Spot are almost all based on natural resources to carry out bamboo forest tourism and sightseeing. Tourists are not involved and cannot participate to experience the bamboo culture, resulting in low visitor satisfaction rate and revisiting rate. Therefore, how to combine the bamboo forest eco-tourism resources, create the Xianning characteristic bamboo forest eco-tourism, and enhance the market competitiveness are the major challenges for the current development. ${ }^{[2]}$

\section{2) Inadequate supporting facilities}

Despite a convenient transportation network in Xianning city, the transportation of such counties as Chongyang, Tongshan and Tongcheng in the south of Xianning is underdeveloped, where the tourism resources of bamboo forest are huge. Some tourism resources are located in mountainous areas, with good access to wide roads and high-speed highways, leading to weak traffic accessibility. Furthermore, the basic supporting facilities are not enough, for example, the local food, accommodation, shopping, entertainment and other service facilities can not keep up with the pace of local eco-tourism development. The insufficient supply of such facilities is bound to cause a psychological gap for and leave a bad impression on tourists. In addition, the investment in tourism funds is insufficient so that there are many problems in the infrastructure system, thus the service facilities are not sound enough, and the supporting systems are not perfect.

\section{3) Weak involvement of residents}

The obvious difference between eco-tourism and traditional mass tourism is that eco-tourism pays much attention to the participation of residents around the scenic spot and advocates that community residents actively participate in the construction of scenic spots. However, for the moment, the participation of villagers around the Zhulin Scenic Spot in Xianning City is not strong enough for the development of scenic spots. Since most of the bamboo forest scenic spots are located in the mountain villages, secluded location and limited education level hinder villagers from having a clear concept of the development of ecotourism, and they do not know much about the profitability of tourism development, so the enthusiasm for the development of the scenic spots is not high. Practically, residents are more willing to engage in traditional bamboo processing and production, due to low investment and rapid profitability. Even worse, some of the more developed scenic spots, such as the Xingxing bamboo zone, have a negative impact on the lives of the surrounding residents due to the influx of tourists, so that some residents reject the development of tourism.

\section{Opportunity Analysis}

\section{1) Increasing popularity of ecological tourism}

In recent years, eco-tourism, as a form of tourism centered on the notion of "returning to nature", has gradually become the first choice of destination for urbanites in the process of making destination decisions. Especially in today's industrialized era, people gradually realize the importance of ecological environmental protection, and are psychologically inclined to eco-type tourism products. The usual stressful work pressure is 
another factor that makes people eager to return to nature and appreciate the original ecological landscape.

Bamboo forest eco-tourism is a combination of the original ecological environment and the long-established bamboo forest culture. It is very attractive to urbanites and is becoming a hot spot in China's forest eco-tourism. Its rise is conducive to solving a series of ecological and environmental problems that have arisen in the process of developing tourism in the scenic spot, so that the bamboo forest tourism will embark on a benign development of eco-tourism road, thereby realizing the sustainable development of bamboo forest eco-tourism. ${ }^{[3]}$

\section{2) Opportunities from the construction of Wuhan City Circle}

Wuhan City Circle refers to the urban circle composed of Wuhan and the surrounding eight cities including Xianning and Huanggang. It is also called " $1+8$ ". This circle incorporates tourism resources and economic strength and realizes crossregional cooperation and development. As the pioneering development zone in the central of the circle, Xianning fully and quickly responded by opening up its tourism and other industries to take full advantage of Wuhan city circle program, maximizing its development and realizing group scale effect. It is projected that Xianning city can be made a part of the triangle hub of Hubei, Hunan and Jiangxi province. ${ }^{[4]}$

\section{Threat Analysis}

\section{1) Increasing market competition}

Nowadays, people's mentality of returning to nature is growing stronger. With a series of policies being introduced, all regions are actively responding to the government's call. Tourism products are constantly emerging, and promotional methods are frequently refurbished, resulting in intense market competition. The surrounding cities of Xianning City also respond to policies and develop tourism products with their own characteristics, which will divide some of the source markets. Although Xianning bamboo forest resources are unique, it will inevitably compete with other tourist areas for market share. Within Hubei province, similar bamboo forest eco-tourism scenic spots include: Yichang Sanxia Ecological Bamboo Scenic Area, Huanggang Luotian Bamboo Forest, Huangshi Xiandao Lake Bamboo Forest, etc. Among them, the first one is most well-known, which is the national AAAA-level tourist scenic spot. It is rich in resources and has the reputation of "natural oxygen bar in the Three Gorges area". It will pose a certain threat to the development of Xianning bamboo forest eco-tourism in the competition for bamboo forest eco-tourism resources.

\section{2) Differentiation of tourists' needs}

With the improvement of people's material life and consumption level, the tourism demand of tourists is increasingly differentiated, and more and more attention is paid to the differentiation and diversification of tourism products. At present, the ecological tourism of Xianning bamboo forest is mainly based on sightseeing and leisure. In the course of the tour, visitors can appreciate nothing but the bamboo and it is easy to cause visual fatigue. The scenic spot mainly relies on its good natural environment, but it does not carry out reasonable planning and development of the scenic spot, and lacks its own brand characteristics. "Although it is in the name of eco-tourism, it is in reality the mass tourism."[5] Therefore, in the face of the diversified needs of tourists, Xianning bamboo forest eco- tourism faces great challenges and needs to enrich its own tourism products.

\section{COUNTERMEASURES FOR BAMBOO FOREST ECO- TOURISM DEVELOPMENT IN XIANNING CITY}

\section{A. Integration of bamboo forest tourism resources and optimization of bamboo forest eco-tourism products}

On the basis of protecting the existing bamboo forest tourism resources, attention should be paid to the development of bamboo forest eco-tourism and explore the bamboo forest cultural tourism resources. Based on the bamboo zones, new tourism products can be developed, such as ecological oxygen bar, bamboo forest museum, bamboo forest club, etc., so as to improve the cultural elements of the scenic spot, enhance Xianning bamboo forest eco-tourism brand, and increase its popularity. The popularity increases the tourist attraction of the scenic spot. For example, in the process of development of Suiyang bamboo forest, it can be combined with special terrain such as streams and mountains to carry out activities such as drifting and rock climbing; Xingxing bamboo zone can be reasonably redesigned and modified so as to involve tourists to participate in such activities as how to make bamboo bonsai; in Chongyang Hongxia bamboo forest, tourists can have to chance to cook by themselves, using bamboo shoots as raw materials, or to make handicrafts and exhibits such as hand-made bamboo baskets, bamboo musical instruments, bamboo lanterns, etc., using only bamboo materials. In this way, bamboo tourism can be more accessible, touchable and colorful with its diverse activities.

\section{B. Coordinating regional ecological and economic development and improving tourism supporting facilities}

In order to further develop Xianning eco-tourism, it is necessary to combine economic development with ecological protection and take the road of green ecological development, to strengthen cooperation between scenic spots and enterprises, to combine bamboo-related industries, health care products and leisure foods to improve the ecological bamboo industrial chain. This will not only improve the economic development of local communities, but also mobilize local residents' and bamboo farmers' enthusiasm for bamboo forest eco-tourism. It is necessary to break through the original model of bamboo forest mass tourism by fully incorporate tourists, local residents and management personnel so as to embark on the real bamboo forest ecotourism road. ${ }^{[5]}$

Through government-enterprise cooperation and other means, it is important to increase capital investment in the construction of bamboo forest scenic spots, carry out scientific and rational planning, improve the tourism infrastructure and supporting facilities, and improve the quality of tourism development. In addition to strengthening the basic facilities construction around "the six elements of tourism", it is necessary to strengthen the construction of the bamboo forest tourism interpretation system, supplementing and improving the bamboo names, habitat and distribution, utilization, etc., setting and repairing the scenic tourist landmarks in a way that is harmonious with the surrounding landscape of the bamboo forest, so that the knowledge of the scenic spot can be displayed to the tourists in an all-round way, and the charm of the bamboo forest eco-tourism can be fully exerted ${ }^{[2]}$ It is also important to design reasonable routes and walking trails to avoid any trampling of forest land and damage to bamboo forest resources, and truly realize green eco-tourism in bamboo forests. 


\section{Grasping the opportunity to promote the development of bamboo forest eco-tourism}

In recent years, although the ecological economy of bamboo forests in Xianning City has developed rapidly, the bamboo forest resources have not been fully developed. Therefore, detailed investigation, systematic research and scientific evaluation of existing bamboo tourism resources should be carried out, comprehensive planning should be formulated to rationally develop and utilize existing resources, and research on bamboo forest ecotourism industry should be carried out to develop ecologically targeted industries. The tourism development plan needs to involve higher education institutions and relevant science research departments, and actively carry out research and discussion on bamboo forest eco-tourism to promote its healthy and stable development. ${ }^{[6]}$ While developing ecotourism resources, it can be integrated with other tourism elements for common development, such as: the Three Kingdoms Culture of Chibi, the massive tea garden, the Lushui Lake, the sweet-scented osmanthus, the hot springs, the Taoist culture of Jiugong Mountain, Yinshui Cave in Tongshan, etc., to create a natural landscape leisure sightseeing tour, ecological tour, adventure tour, village ecological tour, along with natural landscape sightseeing, folk culture, fruit picking and so on to increase tourism Richness.

At present, Xianning is vigorously promoting whole region tourism and creating a tourism framework of "one core, two wings, four poles and four belts". Among them, the "four poles" involve the construction of bamboo forest ecotourism.. Therefore, Xianning City should develop whole region tourism to promote the green rise of Xianning. Under the guidance of the "13th Five-Year Development Plan for Tourism in Xianning City", the city will conscientiously implement relevant planning, make full use of local resource advantages, and create distinctive bamboo forest eco-tourism, so as to promote the overall upgrade of tourism in Xianning City.

\section{CONCLUSION}

Under the background of global tourism, Xianning city should give full play to their advantages, such as good environment, resources, culture, transportation, and take measures to actively respond to the existing shortcomings and threats through the integration of bamboo forest tourism resources, optimization of bamboo forest ecotourism products, and coordination of regional ecological economy development, so as to improve the tourism facilities, and promote Xianning bamboo forest ecotourism and sustainable development.

\section{REFERENCES}

[1] CHI ying ying, LU xiao zhen, CHEN yong jiang Chi Yingying, Lu Xiaozhen, Chen Yongjiang. Eco-tourism development in the bamboo forests at a suburb area in Nanjing [J]. Journal of Jiangsu Forestry Science \& Technology, 2011, 38 (03): 21-24.

[2] Wang Zuli. Study on the problems and countermeasures of the ecological tourism industry in Xianning bamboo forest[J].Journal of Hubei University of Science and Technology, 2014, 34 (03): 8-9.

[3] Chi Yingying. Research on the development of bamboo forest ecotourism in the suburbs of Nanjing [D]. Nanjing Forestry University, 2011.

[4] Hu Min. Study on the countermeasures for the development of ecological tourism in Xianning City[J]. School of Urban and Environmental Sciences, Central China Normal University, 2016.

[5] Zhao Minyan, Dong Wenyuan, Li Bei, et al. SWOT Analysis and Consideration on Bamboo- Forest Ecotourism in China $[\mathrm{J}]$. World Bamboo and Rattan, 2006, (4): 39-42.

[6] Zheng Jinshuang. Discussion on Developing Bamboo Forest Ecotourism in Yongan, Fujian[J]. East China Forest Management, 2006 (01): 22-24. 